\title{
Efficacy of Low-Dose Oral Liquid Morphine for Elderly Patients with Chronic Non-Cancer Pain: Retrospective Chart Review
}

\author{
Joyce Lee $^{1,4} \cdot$ S. Fatima Lakha ${ }^{1,2,3}$ - Angela Mailis ${ }^{1,2,3}$
}

Published online: 18 November 2015

(c) The Author(s) 2015. This article is published with open access at Springerlink.com

\begin{abstract}
Introduction The use of medications among older persons can often be challenging as physiological changes may affect metabolism and cognitive abilities. Several studies show that the elderly with chronic pain are seriously undertreated or inappropriately treated, particularly with respect to opioids.

Objective To determine whether very low doses of oral liquid morphine (LM) in patients over 65 years of age with chronic non-cancer pain provides meaningful pain improvement.

Methods A retrospective chart review was conducted for ten carefully selected older patients seen at a tertiary care pain clinic in Toronto Ontario (2009-2011) with serious biomedical painful conditions and intolerance to other opioid analgesics. Data collected included demographics, LM dosing, diagnosis and average Numeric Rating Scale (NRS) pain ratings pre- and post-administration of LM.

Results Of the ten eligible patients, the female/male ratio was $4: 1$, mean age 75.5 years and mean pain duration 7.9 years. The initial dose of LM for all patients was 1-3 mg three times/day and the maintenance dose ranged
\end{abstract}

Joyce Lee

Joyce.Lee@uhn.ca

1 Comprehensive Pain Program (CPP), Toronto Western Hospital, 750 Dundas St W., Rm. 280, 2nd Floor, Toronto, ON M6J 3S3, Canada

2 University of Toronto Centre for the Study of Pain, Toronto, ON, Canada

3 Institute of Medical Sciences, University of Toronto, Toronto, ON, Canada

4 Daphne Cockwell School of Nursing, Ryerson University, Toronto, ON, Canada from 5 to $30 \mathrm{mg} /$ day. Overall, pain ratings dropped from 6.35 to 2.95 (3.4 point drop on the NRS score) with a mean follow-up of 14 months (range 10-21).

Conclusion The case series showed that carefully selected elderly patients with biomedical pathology can benefit from very low doses of LM. Future larger and well-designed studies need to focus on the use of LM for elderly patients.

\section{Introduction}

Chronic pain in adults older than 65 years of age is a significant problem. Globally, approximately $45-85 \%$ of the older population report chronic pain in different settings [1-4]. Given that the global population is aging, chronic pain will become an even larger problem in the near future [5]. Many factors may contribute to the challenges of managing pain in older adults. The frequent prevalence of co-morbid conditions makes the assessment and treatment of pain quite complex [6]. From the patients' perspective, older adults' pain is not assessed regularly [7], while they tend in general to under-report pain [8]. In one study, as many as $60 \%$ of older adults with pain did not ask for analgesics [9]. From the providers' side, some physicians are reluctant to prescribe analgesics and specifically opioids [10] because of concern with addiction and negative side effects [3]. Nevertheless, the consequences of inadequately treated pain in older individuals are far-reaching and can include impaired function [6], decreased activities of daily living [3] and depression [11].

The most common strategy for the management of persistent pain in older persons is the use of pharmacological agents [6, 12]. A recent study showed that older adults commonly use over-the-counter analgesics and that 
$40 \%$ of them do not experience any benefit from these medications [1, 13]. The American Geriatric Society suggests the administration of opioids in the elderly patients [6]. Opioids have been shown to be effective in reducing pain intensity in different populations with chronic pain conditions [14]. A national Canadian study documented that only $7 \%$ of older adults with moderate to severe pain that interfered with function were receiving opioids stronger than codeine [15]. The Canadian Guideline for Safe and Effective Use of Opioids (2010) recommends that morphine solutions are better options than tablets for PRN (as needed) use in older populations [16]. Furthermore, a recent systematic review suggested that a trial of opioids is appropriate for chronic pain in elderly patients who do not respond to first-line therapies and experience significant pain-related functional impairment [17].

In general, the lowest form of morphine tablet or equivalent is $5 \mathrm{mg}$, which may not be tolerated in elderly populations. However, liquid morphine (LM) concentration is available as $1 \mathrm{mg} / \mathrm{ml}$. Thus, we considered trialing LM (1-3 $\mathrm{mg} / \mathrm{ml}$ three times/day) in our population to improve their pain. The aim of the retrospective case series study, therefore, was to report the effect of LM in the management of persons 65 years and older with chronic noncancer pain (CNCP) and provide in-depth information on the characteristics of patients administered LM.

\section{Methods}

We undertook a retrospective case study of ten patients aged 65 years or older who were seen in a tertiary care pain programme at a Canadian academic hospital during the period 2009-2011. Patients included in the case series were those with significant painful biomedical pathology who had failed other treatments including opioid analgesics and/ or were considered inoperable. These patients were considered eligible by the pain consultants to receive LM if (a) there were no medical contraindications (such as severely reduced kidney function) and (b) the patients were cognitively and physically capable of managing their medications or they had adequate supervision if opioids were to be prescribed.

Data were collected routinely at the time of original consultation for all patients seen in the clinic. Upon arriving at the clinic for their initial visit, patients were asked to complete a standardized intake form that included the following information: age, gender, marital status, country of origin, education, employment status and body map where the patients marked the areas of pain and pain ratings. All patients were then interviewed, examined and diagnosed by one of the pain clinic physicians with regard to the underlying clinical condition and medical, cognitive and psychiatric co-morbidities, while average Numeric Pain Scale Ratings (NRS) were obtained at the time of the interview. The physicians decided subsequently who the candidates for LM would be (based on the presence of detectable biomedical pathology shown to respond to opioids and absence of significant psychiatric co-morbidity), taking cognitive and psychosocial factors into account.

For the case series, additional data were extracted from clinical charts as follows: (a) type/mechanism of injury or disease; (b) duration of pain condition; (c) types of pain conditions if more than one; (d) current pharmacological treatments including type and dosages of opioids (and/or liquid morphine) as well as list of tricyclic antidepressants, anticonvulsants, sedatives and hypnotics (without details of dose); (e) list of co-morbidities; and (f) adverse drug reaction (ADR) relating to LM administration. Additionally, we retrieved information about living conditions, psychosocial factors and support systems for the patients. All medications were reported using generic names. Treatment regimen, possible ADR and equianalgesic dose information for each opioid type is adapted from the Canadian Guideline group for Safe and Effective Use of Opioids for CNCP [16]. To determine the accuracy of the reported prescription information, consultants examined actual pharmacy prescription records when available, medical records documenting prescriptions and/or labeled prescription containers.

The first follow-up after initiating LM was usually in 1 month. Subsequent follow-up visits were anywhere from 1 to 3 months, based on the needs of the patients.

The intensity of pain was obtained verbally from the patients at the time of their assessment by the clinicians on an 11-point NRS, on initial and all follow-up visits. The end-points of the scale were defined as "no pain" $(\mathrm{NRS}=0)$ and "maximum pain" $(\mathrm{NRS}=10)$ as the worst imaginable pain. A pain rating from 1 to 3 was considered mild pain, 4 to 6 moderate, and pain ratings $\geq 7$ were considered severe pain. Assessment of pain relief was based on the change in pain severity from baseline (prior to initiation of LM) to the last follow-up visit. In order to detect a clinically relevant response to treatment, a "responder" was defined as a patient experiencing a reduction in the NRS baseline score by 2 points or $30 \%$ at any time after initiation of LM.

\section{Results}

\subsection{General Characteristics}

Of the ten eligible patients, the female to male ratio was $4: 1$ (eight females, two males) with a mean age of 75.5 (range $67-88$ years) and mean pain duration of 7.9 years. Other 
demographic characteristics, diagnosis and co-morbidities are summarized in Table 1. Based on pain drawings, the lower extremities were the most common pain site.

\subsection{Pharmacological Treatment}

Prior to the referral to our clinic seven patients had been tried on different forms of opioids (tramadol, oxycodone or oxycodone/ acetaminophen) and were discontinued due to side effects (particularly nausea, constipation and somnolence) or did not find them effective. At the point of entry to the clinic, four patients were on opioids with a mean equivalent dose of morphine (MED) of 6.3 (range 1.2-15) mg per day. The most frequently prescribed opioid was acetaminophen + codeine (3/4). Detailed pharmacological treatment and current coprescriptions are illustrated in Table 2.

\subsection{Baseline Pain Characteristics}

With regard to the NRS pain rating at the initial visit, four patients rated their average pain as severe (NRS score $\geq 7$ ) and six patients rated their average pain as moderate (NSR score 4-6). The mean average pain ratings of all patients at baseline were 6.35 (range 5-9) with duration of pain from 6 months to 21 years.

\subsection{Initiation and Response to Liquid Morphine}

Based on case-to-case and on the clinical judgement of the clinician, LM 1-3 mg, three times a day was initiated and adjusted as needed. The maintenance dose of LM for all patients ranged from 5 to 30 (mean 19.05) $\mathrm{mg} /$ day. Details of the LM dose and pain intensity scores for all patients extracted at the initial and last visit during the study period are shown in Table 3.

All patients reported an overall reduction of pain with use of LM over the study period. The mean NRS scores for the ten patients decreased from baseline measurements of 6.35-2.95 (3.4-point drop) once they reached maintenance doses of LM (median $17.5 \mathrm{mg}$, range 5-30 mg). Subsequently some patients were converted to morphine tablets, which they were able to tolerate after extremely slow

Table 1 Demographics, diagnosis and co-morbidities of study patients (aged $>65$ years with chronic non-cancer pain)

\begin{tabular}{|c|c|c|c|c|c|}
\hline Patient & $\begin{array}{l}\text { Age, } \\
\text { years }\end{array}$ & Gender & $\begin{array}{l}\text { Living } \\
\text { arrangement }\end{array}$ & Diagnosis & Co-morbidities \\
\hline 1 & 72 & Female & $\begin{array}{l}\text { Lives alone in } \\
\text { condo }\end{array}$ & $\begin{array}{l}\text { Mechanical back pain (scoliosis and } \\
\text { degenerative changes) }\end{array}$ & Irritable bowel syndrome, osteoporosis, GERD \\
\hline 2 & 75 & Female & $\begin{array}{l}\text { Lives with } \\
\text { husband in } \\
\text { house }\end{array}$ & $\begin{array}{l}\text { Diabetic neuropathy, mechanical } \\
\text { back pain, joint OA }\end{array}$ & $\begin{array}{l}\text { Diabetes, hypertension, hypercholesterolaemia, asthma, } \\
\text { Bell's palsy, right-sided stroke, migraines/headaches }\end{array}$ \\
\hline 3 & 72 & Female & $\begin{array}{l}\text { Lives with } \\
\text { husband in } \\
\text { house }\end{array}$ & $\begin{array}{l}\text { Small fibre peripheral neuropathy, } \\
\text { joint OA }\end{array}$ & Crohn's disease, $\mathrm{HCV}$ \\
\hline 4 & 87 & Male & $\begin{array}{l}\text { Lives alone in } \\
\text { condo }\end{array}$ & $\begin{array}{l}\text { Peripheral neuropathy and chronic } \\
\text { L5 radiculopathy, mechanical neck } \\
\text { pain }\end{array}$ & Hypercholesterolaemia, gout, BPH \\
\hline 5 & 78 & Female & $\begin{array}{l}\text { Lives with } \\
\text { husband in } \\
\text { house }\end{array}$ & $\begin{array}{l}\text { L5 radiculopathy, peripheral } \\
\text { neuropathy, left peroneal nerve } \\
\text { injury, frozen shoulder }\end{array}$ & $\begin{array}{l}\text { Non-Hodgkins' lymphoma, hypertension, } \\
\text { hypothyroidism }\end{array}$ \\
\hline 6 & 68 & Female & $\begin{array}{l}\text { Lives with } \\
\text { husband in } \\
\text { house }\end{array}$ & $\begin{array}{l}\text { Lumbar, radiculopathy, peripheral } \\
\text { neuropathy, chronic cervical } \\
\text { radiculopathy }\end{array}$ & $\begin{array}{l}\text { Diabetes, GERD, hypercholesterolaemia, hypertension, } \\
\text { depression, giant cell tumour, OA, bilateral Charcot } \\
\text { joint neuroarthropathy }\end{array}$ \\
\hline 7 & 72 & Male & $\begin{array}{l}\text { Lives with } \\
\text { family in } \\
\text { apartment }\end{array}$ & $\begin{array}{l}\text { Diabetic neuropathy, spinal stenosis, } \\
\text { lumbar radiculopathy, mechanical } \\
\text { back pain }\end{array}$ & $\begin{array}{l}\text { Parkinson's disease, diabetes, hypertension, } \\
\text { hypercholesterolaemia, cardiac disease, bladder cancer }\end{array}$ \\
\hline 8 & 78 & Female & $\begin{array}{l}\text { Lives with } \\
\text { husband in } \\
\text { house }\end{array}$ & Mechanical back and neck pain & Hypertension, hypercholesterolaemia, glaucoma \\
\hline 9 & 83 & Female & $\begin{array}{l}\text { Lives alone in } \\
\text { condo with } \\
\text { outside help }\end{array}$ & $\begin{array}{l}\text { Lumbar radiculopathy, spinal } \\
\text { stenosis }\end{array}$ & $\begin{array}{l}\text { OA of knees, osteopenia, angina, hypertension, } \\
\text { hyperlipidaemia, hiatus hernia }\end{array}$ \\
\hline 10 & 70 & Female & $\begin{array}{l}\text { Lives alone in } \\
\text { apartment }\end{array}$ & $\begin{array}{l}\text { Lumbar radiculopathy, mechanical } \\
\text { back pain }\end{array}$ & Hypertension, essential tremor, depression \\
\hline
\end{tabular}

condo condominium, GERD gastroesophageal reflux disease, $H C V$ hepatitis $\mathrm{C}$ virus, $O A$ osteoarthritis 


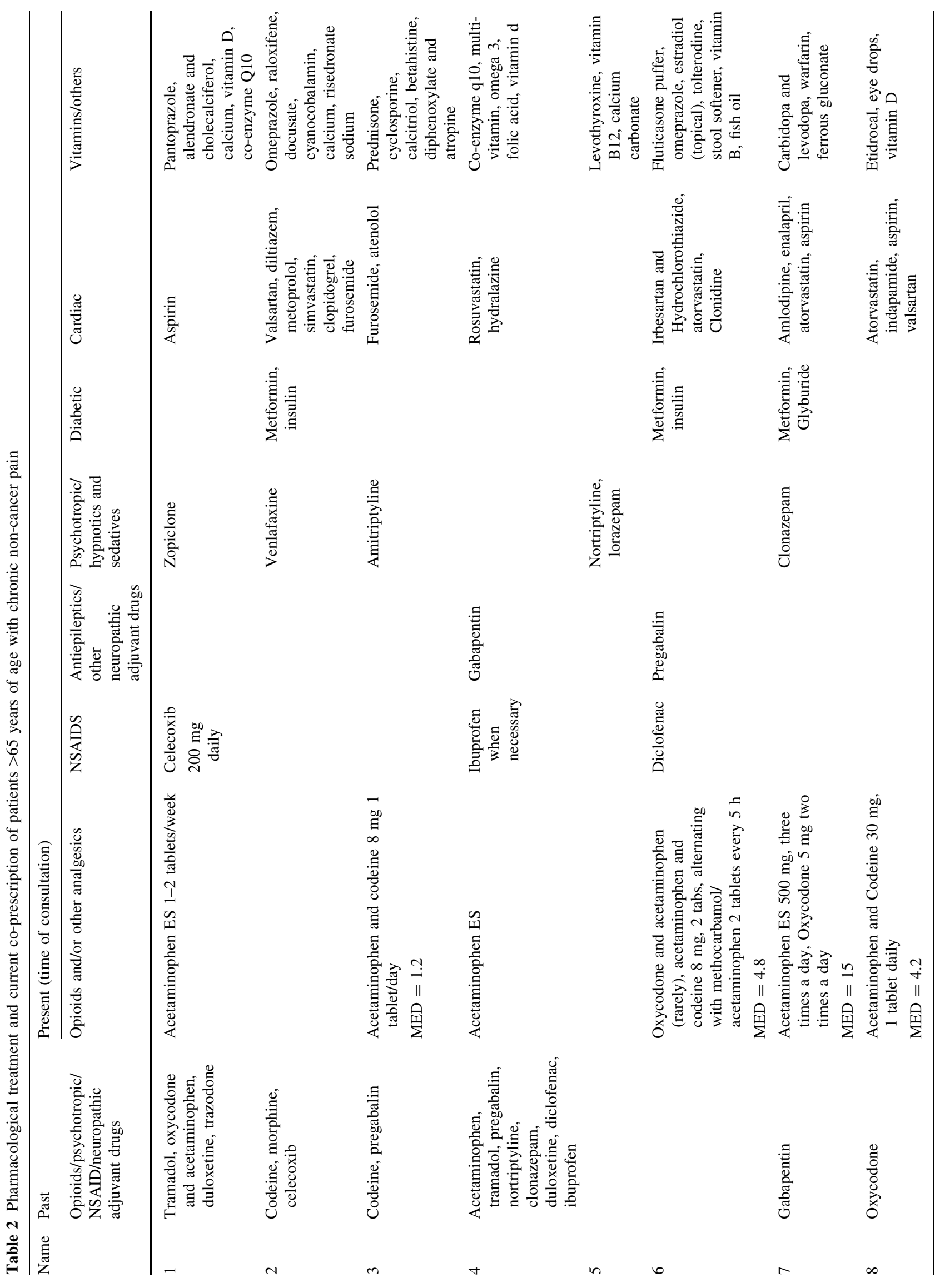




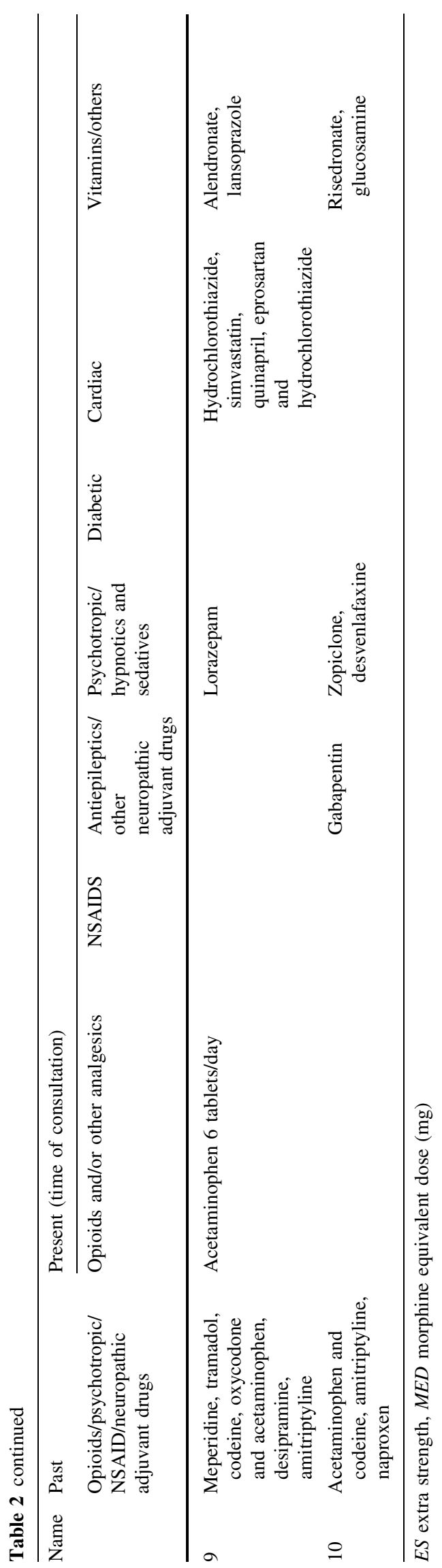

titration with LM. All the patients were titrated at different time-points their follow-up. The first follow-up after initiating LM was 1 month and last follow-up of these patients averaged 14 months.

ADRs were mild and none led to discontinuation of LM as they were managed conservatively (by increasing dietary fibers, fluid intake, etc.). Details of ADRs are shown in Table 3.

\section{Illustrative Case Reports}

\subsection{Case Report 1}

A 72-year-old widower, living with two of his daughters in an apartment, was referred for management of back/leg pain. He had a previous history of lumbar spine surgery in 1998. One year prior to referral to our pain clinic, low back pain recurred spontaneously and started radiating to the left leg. Electrophysiological studies demonstrated diabetic neuropathy and chronic left L5 radiculopathy, while CAT scan showed L3-5 advanced degenerative changes with moderate to severe canal stenosis and foraminal impingement. Back and leg pain was rated as $9 / 10$ with a range of $0 / 10$ to $10 / 10$. He was not considered a good surgical candidate due to medical co-morbidities.

Medications on consultation Acetaminophen extra strength $500 \mathrm{mg}$ three times a day, oxycodone $5 \mathrm{mg}$ tablet two times a day (which he avoided taking most of the times because it was too strong); metformin, carbidopa and levodopa, warfarin, atorvastatin, clonazepam, amlodipine, ferrous gluconate, enalapril, glyburide and aspirin.

Co-morbidities Parkinson's disease, type 2 diabetes, coronary artery bypass graft (CABG) and mechanical aortic valve replacement, hypertension and hypercholesterolaemia, left total knee replacement and bladder cancer with previous surgeries.

Treatment On the first visit, gabapentin was initiated for neuropathic pain in low doses. He developed light-headedness and fatigue with no improvement in his pain, which remained $9 / 10$ fluctuating from $0 / 10$ to $9 / 10$ and averaging $6 / 10$ (similar ratings to his initial visit). On the second visit LM was initiated and he was switched to low-dose pregabalin (which ultimately was better tolerated). On the third visit, there was some improvement in his pain, which was rated as $5-6 / 10$. We found out that the patient was using pregabalin regularly but LM scantily and was advised to use LM regularly. In subsequent visits both LM and pregabalin were gradually titrated upwards. He experienced daytime somnolence with pregabalin, which remained unchanged at $75 \mathrm{mg}$ am and $150 \mathrm{mg}$ at bedtime for the subsequent duration of the study. Upwards titration of LM continued. At his last follow-up (10 months after the 


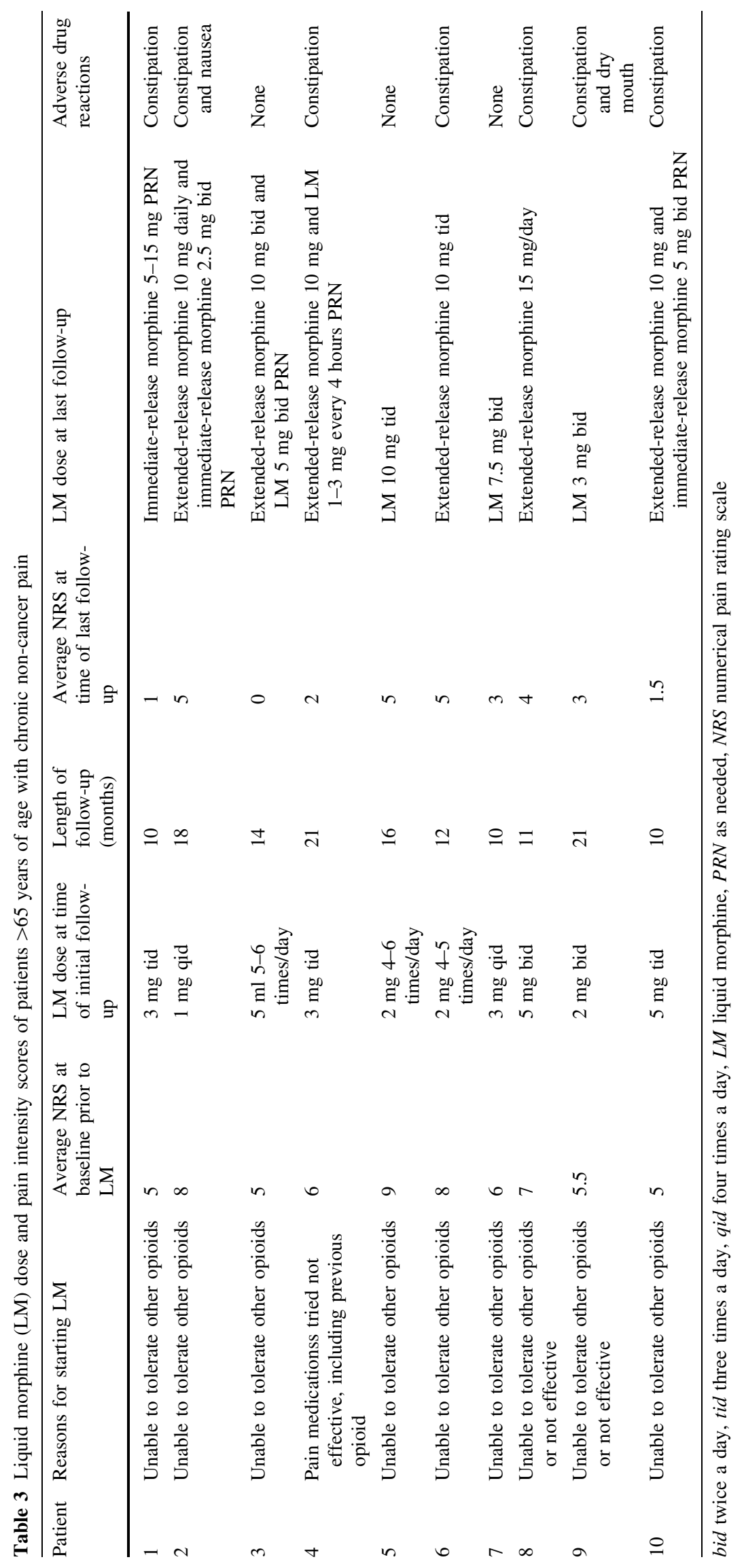


initial visit), pain was manageable with LM $7.5 \mathrm{mg}$ twice a day and pregabalin $75 \mathrm{mg}$ in the morning and $150 \mathrm{mg}$ at bedtime. The patient refused to switch LM to tablets because he preferred the liquid form of morphine. He consistently rated his low back and left leg pain as average $3 / 10$, a level he was satisfied with and felt that his functioning had substantially improved.

\subsection{Case Report 2}

A 70-year-old female divorcee living independently in an apartment was referred for management of low back/leg pain. She developed gradual onset of low back pain 12 years earlier that she attributed to lifting patients, as she was a psychiatric nurse. Two years prior to referral to the pain clinic she developed right leg pain and paraesthesiae. She rated her back/leg pain during the initial interview as $2 / 10$ fluctuating from $0 / 10$ to $10 / 10$ with an average of $5 / 10$. Lumbar X-ray showed severe lumbar scoliosis convex to the right L3 and severe degenerative disc and facet joint disease with compression fracture of L4. Magnetic resonance imaging (MRI) of the lumbar spine demonstrated advanced multilevel degenerative changes; compression of the right traversing S1 nerve root; severe narrowing of the L5-S1 right foramina with compression of the exiting L5 nerve root; and multifocal degenerative central canal stenosis. EMG/NCT demonstrated mainly chronic right L5 radiculopathy. She was not considered a surgical candidate due to the extent of degenerative changes.

Medications on consultation Gabapentin $300 \mathrm{mg}$ three times a day, risidronate, desvenlafaxine, zopiclone and glucosamine. Gabapentin caused grogginess and had little effect on the shooting pain.

Co-morbidities Hypertension, essential tremor and depression.

Treatment On first visit, LM was initiated, with instruction to start with $3 \mathrm{mg}$ three times a day PRN and to increase the dose by $1 \mathrm{mg}$ every 3 days up to $5 \mathrm{mg}$ three times a day. On the first follow-up visit the patient indicated that she tried LM up to $5 \mathrm{mg}$ three times a day and felt more energetic, did not need to nap during the day, and slept well during the night. She rated her pain as $0 / 10$ in the morning, 3/10 at noon and 7/10 at night. On the next visit, LM had been increased to $5 \mathrm{mg}$ four times a day and she was able to walk longer with less pain and felt more confident. She rated the pain as $0 / 10$ in morning and $2-3 / 10$ during the day. In subsequent visits, she elected to reduce gabapentin to $100 \mathrm{mg}$ three times a day and gradually she was switched to extended-release morphine $10 \mathrm{mg}$ daily and immediate-release morphine $5 \mathrm{mg}$ as needed (1-2 tablets/day). On her last visit (10 months later) she was stable on extended-release morphine $10 \mathrm{mg}$ daily and immediate-release morphine $5 \mathrm{mg}$ PRN (1-2 tablets/day) and had stopped gabapentin. Low back and right leg pain were consistently rated as $1.5 / 10$.

\section{Discussion}

In the present case series, we observed that all elderly patients $(n=10)$ in this series, with a mean age of 75.5 years and substantial medical co-morbidities, responded positively to the use of LM with a clinically meaningful reduction in pain ratings and increase in function. It should be noted that we took extra care to ensure patients were safe taking morphine while living independently in the community or with family members that could provide supervision. LM was initiated at 1-3 mg three times a day and adjusted as needed; patients were followed regularly starting 1 month after the initial visit with the last follow-up at 14 months on average. On their last follow-up, the mean average NRS scores were reduced from 6.35 at baseline to 2.95 (3.4-point drop), with a maintenance dose range of LM from 5 to $30 \mathrm{mg}$ morphine equivalent dose. In some cases the combination of a disease-specific drug and morphine resulted in good pain relief. In the end, most patients were successfully converted to oral morphine tablets (alone or in combination with LM).

Formulating an effective treatment plan for older patients with persistent pain requires a clear understanding of their co-morbidities and psychosocial situation [17] as biomedical pathology and co-morbidities are indeed very high in older patients [18-20]. When one prescribes medications in the elderly, certain factors should be taken into account beyond co-morbidities, such as an increase in pain threshold and physiological decline in hepatic and renal function that may affect the pharmacology of analgesics including onset of action, elimination rate and half-life of the drug [21].

Existing guidelines for chronic pain management [16, 21] recommend that opioid therapy for elderly patients can be safe and effective with appropriate cautions, including lower starting doses, slower titration, longer dosing interval and more frequent monitoring.

The availability of morphine in concentrations as low as $1 \mathrm{mg} / \mathrm{ml}$ in liquid form means that the clinician can start with minimal doses and titrate slowly over longer periods to monitor ADRs and pain response. While opioid-related ADRs (primarily constipation, nausea, dizziness and somnolence) are very well documented in the literature [3, 22] and were similar in our case studies, they were managed conservatively and none of our patients discontinued therapy because of ADRs.

In a recent meta-analysis on the effective treatment of older patients with persistent pain, the reviewed studies 
were short-term in nature (12 weeks or less) and participants were aged in their sixties to seventies with no significant co-morbidities [17]. However, in the present case series, most patients had at least three co-morbidities and were followed up on average for 14 months.

\section{Conclusion}

This case series showed that select elderly patients can benefit from the use of very low doses of LM, while they had been intolerant of other medications. In some, the very slow titration of LM over weeks and months allowed for transition to low-dose tablets, something that was not possible before with oral medications. Future larger, welldesigned studies need to focus on exploring further use of LM and its impact on pain ratings and quality of life for older patients.

\section{Compliance with Ethical Standards}

Ethical approval Received approval from University Health Network research ethics board before chart reviewed.

Conflict of interest The authors Joyce Lee, Fatima Lakha and Dr Angela Mailis declare that they have no conflicts of interest.

Funding This research received no specific grants from any funding agency in the public, commercial or not-for-profit sectors.

Open Access This article is distributed under the terms of the Creative Commons Attribution-NonCommercial 4.0 International License (http://creativecommons.org/licenses/by-nc/4.0/), which permits any noncommercial use, distribution, and reproduction in any medium, provided you give appropriate credit to the original author(s) and the source, provide a link to the Creative Commons license, and indicate if changes were made.

\section{References}

1. Gianni W, Ceci M, Bustacchini S, et al. Opioids for the treatment of chronic non-cancer pain in older people. Drugs Aging. 2009;26:63-73.

2. Helme RD, Gibson SJ. The epidemiology of pain in elderly people. Clin Geriatr Med. 2001;17:417-31.

3. Papaleontiou M, Henderson CR Jr, Turner BJ, et al. Outcomes associated with opioid use in the treatment of chronic noncancer pain in older adults: a systematic review and meta-analysis. J Am Geriatr Soc. 2010;58(7):1353-69.

4. Soldato M, Liperoti R, Landi F, et al. Non-malignant daily pain and risk of disability among older adults in home care in Europe. Pain. 2007;129(3):304-10.
5. Beard JR, Biggs S. Bloom DE, et al., editors. Global population aging: peril or promise. Geneva, Switzerland: World Economic Forum; 2012. Available at http://www.weforum.org/reports/ global-population-ageing-peril-or-promise. Accessed 30 Aug 2015.

6. American Geriatric Society Panel. Pharmacological management of persistent pain in older persons. J Am Geriatr Soc. 2009;57:1331-46.

7. Pickering G, Jourdan D, Dubray C. Acute versus chronic pain treatment in Alzheimer's disease. Eur J Pain. 2006;10(4):379-84.

8. Robinson CL. Relieving pain in the elderly. Health Progress. 2007;88(1):48-53.

9. Jonas-Simpson C, Mitchell GJ, Fisher A, Jones G, Linscott J. The experience of being listened to: a qualitative study of older adults in long-term care settings. J Gerontol Nursing. 2006;32(1):46-53.

10. Spitz A, Moore AA, Papaleontiou M, Granieri E, Turner BJ, Reid MC. Primary care providers' perspective on prescribing opioids to older adults with chronic non-cancer pain: a qualitative study. BMC Geriatr. 2011;11(35):1-9.

11. Mossey JM, Gallagher RM. The longitudinal occurrence and impact of comorbid chronic pain and chronic depression over two years in continuing care retirement community residents. Pain Med. 2004;5(4):335-48.

12. Barber JB, Gibson SJ. Treatment of chronic non-malignant pain in the elderly: safety considerations. Drug Saf. 2009;32(6):457-74.

13. Breivik H, Collett B, Ventafridda V, Cohen R, Gallacher D. Survey of chronic pain in Europe: prevalence, impact on daily life, and treatment. Eur J Pain. 2006;10(4):287-333.

14. Furlan AD, Sandoval JA, Mailis-Gagnon A, Tunks E. Opioids for chronic noncancer pain: a meta-analysis of effectiveness and side effects. Can Med Assoc J. 2006;174:1589-94.

15. Moulin D, Clark AJ, Speechley M, Morley-Forster PK. Chronic pain in Canada-prevalence, treatment, impact and the role of opioid analgesia. Pain Res Manag. 2002;7(4):179-84.

16. Canadian guideline for safe and effective use of opioids for chronic non-cancer pain version 4.5 National Opioid Use and Guideline Group, 2010. Retrieved from http://nationalpaincentre. mcmaster.ca/opioid/. Accessed 3 Aug 2015.

17. Makris UE, Abrams RC, Gurland B, Reid MC. Management of persistent pain in the older patient: a clinical review. JAMA. 2014;312(8):825-36.

18. Mailis-Gagnon A, Nicholson K, Yegneswaran B, Zurowski M. Pain characteristics of older adults 65 and over referred to a tertiary care pain clinic. Pain Res Manag. 2008;13(5):389-94.

19. Wolff JL, Starfield B, Anderson G. Prevalence, expenditures, and complications of multiple chronic conditions in the elderly. Arch Intern Med. 2002;162:2269-76.

20. Guralnik JM. Assessing the impact of comorbidity in the older population. Ann Epidemiol. 1996;6:376-80.

21. Pergolizzi J, Böger RH, Budd K, Dahan A, Erdine S, Hans G, Kress HG, Langford R, Likar R, Raffa RB, Sacerdote P. Opioids and the management of chronic severe pain in the elderly: consensus statement of an International Expert Panel with focus on the six clinically most often used World Health Organization Step III opioids (buprenorphine, fentanyl, hydromorphone, methadone, morphine, oxycodone). Pain Pract. 2008;8(4):287-313.

22. Noble M, Tregear SJ, Treadwell JR, Schoelles K. Long-term opioid therapy for chronic noncancer pain: a systematic review and meta-analysis of efficacy and safety. J Pain Symptom Manag. 2008;35(2):214-28. 